\section{Genetics of the fuzzless ovule phenotype of Gossypium arboreum accession PI 615733 (cv. Zi-Hua Guang Zi)}

\section{John E. Erpelding ${ }^{1 *}$}

Abstract: Lint and fuzz are the two types of fiber that develop on cotton seeds. Lint is an economically important fiber used in the textile industry. Fuzz fibers remain attached to seeds, and reducing the amount of fuzz could improve ginning efficiency. The Gossypium arboreum accession PI 615733 from the United States Department of Agriculture cotton germplasm collection showed the fuzzless trait, where no fuzz fibers were observed on seeds. Accession PI 615733 was crossed with the fuzzy seeded G. arboreum accession PI 529729 to develop an $F_{2}$ population. Seeds from $F_{1}$ plants showed no fuzz fiber. For the $F_{2}$ population of 409 plants, 239 plants were classified as fuzzless and 170 were classified as fuzzy. These data support a two-gene model with incomplete dominance. A greater understanding of the genetic mechanisms controlling fiber development on cotton seeds could contribute to breeding efforts to improve lint fiber yields and quality.

Keywords: Asiatic cotton, fuzz fiber, germplasm, naked-seed, ovule trichome.

\section{INTRODUCTION}

Cotton (Gossypium spp.) is an important agricultural commodity with a wide range of uses, but it is primarily used as a source of natural fiber for the textile industry. In 2018, cotton was produced in 77 countries on approximately 33 million ha, which represents approximately $2 \%$ of the global arable acreage (https://apps.fas.usda.gov/psdonline/app/index.html\#/app/downloads). More than 25.9 million Mt of seed cotton were produced in 2018 with China, India, United States, Brazil, and Pakistan producing approximately $78 \%$ of the cotton fiber worldwide (https://apps.fas.usda.gov/psdonline/app/index.html\#/app/ downloads). The United States is the leading exporter of cotton fiber. There are more than 50 cotton species in the Gossypium genus, with four species, G. hirsutum L. (upland cotton), G. barbadense L. (pima cotton), G. arboreum L. (desi cotton), and $G$. herbaceum L. (levant cotton), cultivated for the production of spinnable fiber (Hutchinson et al. 1945, Wendel et al. 1989, Applequist et al. 2001, Zhang et al. 2008). The two allotetraploid species, G. hirsutum and G. barbadense, represent approximately $98 \%$ of worldwide cotton fiber production, with G. hirsutum accounting for more than 95\% of this total (Zhang et al. 2008, Zhu et al. 2019), and these species originated in the New World (Wendel 1989). Gossypium arboreum and $G$. herbaceum are diploid species and are referred to as Old World or Asiatic cottons (Hutchinson 1935, Wendel et al. 1989). Prior to the introduction of $G$. hirsutum into Asia, $G$. arboreum was widely cultivated
Crop Breeding and Applied Biotechnology 20(4): e32812044, 2020 Brazilian Society of Plant Breeding. Printed in Brazil http://dx.doi.org/10.1590/198470332020v20n4a57

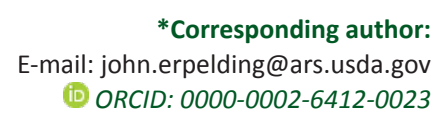

Received: 18 May 2020 Accepted: 19 August 2020 Published: 15 October 2020

\footnotetext{
${ }^{1}$ United States Department of Agriculture, Agricultural Research Service, Crop Genetics Research Unit, 38776, Stoneville, Mississippi,
} United States 
in Asia, the Middle East, and Northeastern Africa (Guo et al. 2006). Due to lower fiber yields and quality, G. arboreum cultivars account for less than $2 \%$ of worldwide cotton fiber production (Zhang et al. 2008, Liu et al. 2015, Romeu-Dalmau et al. 2015, Dewan et al. 2017, Zhu et al. 2019). Nonetheless, G. arboreum cultivars are adaptable to environmental extremes and are still cultivated in regions of Asia under low-input production systems (Iqbal et al. 2015, Romeu-Dalmau et al. 2015, Dewan et al. 2017). Gossypium arboreum cultivars have been evaluated as a source of tolerance to drought and saline soils, of resistance to pests and diseases, and of genetic diversity for fiber and seed quality traits for use in cotton improvement programs (Mehetre et al. 2003, Ma et al. 2008, Maqbool et al. 2010, Erpelding and Stetina 2018).

Two types of fiber, lint and fuzz, develop on cultivated cotton seeds and grow as single cell trichomes from the epidermal layer of the ovule (Hutchinson 1935, Stewart 1975, Applequist et al. 2001, Zhang et al. 2007, Wan et al. 2016). Lint fibers are used in the textile industry. The two fiber types show different developmental processes on the ovule (Zhang et al. 2007). Lint fibers are initiated on or before the day of anthesis and showed greater elongation rates than fuzz fibers (Stewart 1975). For G. hirsutum cultivars, lint fiber lengths typically range from $25 \mathrm{~mm}$ to $35 \mathrm{~mm}$ (Stewart 1975, Qin et al. 2019, Huang et al. 2020), whereas lint fiber lengths can exceed $60 \mathrm{~mm}$ in G. barbadense cultivars (Kim and Triplett 2001). Lint fiber lengths for G. arboreum cultivars range from $15 \mathrm{~mm}$ to $30 \mathrm{~mm}$ (Hutchinson 1935, Applequist et al. 2001, Hande et al. 2017, Huang et al. 2020). Slower elongation rates and earlier fiber termination contribute to the shorter lint fiber lengths for G. arboreum cultivars (Huang et al. 2020). Fuzz fibers are substantially shorter with elongation lengths typically less than $0.5 \mathrm{~mm}$, and these fibers are generally initiated 4 days after anthesis (Stewart 1975, Zhang et al. 2007, Qin and Zhu 2011). Fuzz fibers also remain attached to the seed coat after ginning, giving seeds a fuzzy appearance. The fuzz fibers attached to ginned seeds are referred to as linters in the commercial seed cotton trade (Hebert and Thibodeaux 1988, Bardak and Bölek 2016). One strategy to improve lint yield and ginning efficiency is to reduce the amount of fuzz fibers produced on the ovule (Bechere et al. 2012). Mutations have been identified for fiber development in cotton that can be used to characterize fiber-specific genes (Hutchinson 1935, Rong et al. 2005, Lee et al. 2006, Wang et al. 2008, An et al. 2010). Four independent genes that inhibit fuzz fiber development on the seed coat have been identified in G. hirsutum. Ware (1940) and Ware et al. (1947) identified one dominant $\left(N_{1} N_{1}\right)$ and one recessive $\left(n_{2} n_{2}\right)$ gene conferring the fuzzless ovule phenotype. Turley and Kloth (2002) reported a second recessive gene $\left(n_{3} n_{3}\right)$ and Bechere et al. (2012) identified a third (naked-tufted) recessive gene $\left(n_{4}^{t} n_{4}^{t}\right)$. The $N_{1}$ locus was mapped to chromosome A12 and was associated with a MYB25-like candidate gene (Rong et al. 2005, Wan et al. 2016). The $n_{2}$ locus was mapped to the homoeologous chromosome D12 and was also associated with a MYB25-like candidate gene (Zhu et al. 2018). Expression of the $n_{2}$ phenotype requires expression of the recessive $n_{3}$ locus (Turley and Kloth 2002) and expression of $n_{2}$ is also influenced by environmental conditions and the parental genotype (Zhu et al. 2018). These mutations resulted in little to no fuzz fiber produced on the seed coat; however, segregating populations developed from crosses with these genotypes show quantitative variation for fuzz fiber development (Ware 1940, Bechere et al. 2012). The ginned seeds from these fuzzless ovule genotypes appear as black seeds, which have been referred to as naked-seed (Ware et al. 1947) or naked-tufted for genotypes, in which fibers remain attached to the chalazal and micropylar regions of the seed (Bechere et al. 2012). The fuzzless ovule phenotype has also been reported in G. arboreum genotypes with dominant and recessive genes conferring the fuzzless trait (Hutchinson 1935, Rong et al. 2005, Desai et al. 2008, Wang et al. 2008, Erpelding 2017). Genetic diversity for the fuzzless trait, however, is unknown for accessions in the United States Department of Agriculture (USDA), National Plant Germplasm System (NPGS) G. arboreum collection. The majority of the fuzzless accessions in the collection have not been genetically characterized. Accession PI 615733 showed the fuzzless ovule phenotype, and the aim of this study was to determine the genetic inheritance of this trait for the accession. An $\mathrm{F}_{2}$ population was developed by crossing PI 615733 with a fuzzy ovule G. arboreum genotype from the germplasm collection for phenotypic characterization. A greater understanding of the genetics of the fuzzless trait is important because this information can be used in future studies to determine the pathways for fiber development in cotton.

\section{MATERIAL AND METHODS}

Gossypium arboreum accession PI 615733 (inventory ID A2 232) was donated to the NPGS cotton collection in 2001 as cultivar Zi-Hua Guang Zi (https://npgsweb.ars-grin.gov/gringlobal/accessiondetail.aspx?id=1613750) and was of Chinese origin (Kantartzi et al. 2009). During a seed increase of accessions from the NPGS G. arboreum collection, PI 615733 was phenotypically characterized as having ovules lacking fuzz fiber development. The accession also showed heterogeneity 
for plant stem pigmentation and floral petal spot traits. Red pigmented plants had flowers with red petal spots and green nonpigmented plants had flowers with no petal spots. These two distinct phenotypes within the accession showed the fuzzless ovule trait, and individual plants were selected from the accession and self-pollinated over two generations in the field for seed purification to develop lines representing the two phenotypes. The red pigmented phenotype was more frequent within the accession and selected for genetic characterization of the fuzzless ovule trait, although both phenotypes showed the same growth habit and were similar for other phenotypic traits. Additionally, no obvious withinphenotype segregation for phenotypic traits was observed for the two phenotypes during seed purification.

Accession PI 615733 was used as the female parent in crosses with G. arboreum accession PI 529729 as the male parent to characterize the fuzzless ovule phenotype. Accession PI 529729 (inventory ID A2 101) was donated to the NPGS cotton collection in 1989 as cultivar Garo Hill (https://npgsweb.ars-grin.gov/gringlobal/accessiondetail.aspx?id=1424665) and was selected as a parent because seeds for the accession showed profuse fuzz fiber development. Single plant selections were also conducted for PI 529729; however, self-pollinated flowers frequently aborted, requiring the use of open-pollinated seeds for this accession (Erpelding and Stetina 2018). Seeds from the single plant selections for each accession were planted in single row plots in the field at the USDA in Stoneville, Mississippi (lat $33^{\circ} 25^{\prime} 26^{\prime \prime} \mathrm{N}$, long $90^{\circ} 54^{\prime} 54^{\prime \prime} \mathrm{W}$, alt $38 \mathrm{~m}$ asl, and a Bosket very fine sandy loam soil type). Plants within each row were phenotypically characterized to confirm uniformity prior to conducting crosses in 2012. The standardized cotton descriptors (https:// www.cottongen.org/data/trait/NCGC_rating_scale) were used for phenotypic characterization of the parental genotypes. Accessions PI 615733 and PI 529729 are phenotypically similar for numerous traits, including laciniate-shaped leaves with five major lobes, red pigmented stems, and flowers with red petal spots. However, flower color differs for the two accessions, with PI 615733 having yellow-colored corolla whereas PI 529729 has white-colored corolla (Erpelding and Stetina 2018). Boll and fiber characteristics also differ for the accessions, with PI 615733 having brown lint and PI 529729 having white lint. Additionally, PI 529729 is taller and later-flowering than PI 615733.

Hybrid seeds from one cross were acid-delinted in a 93\% sulfuric acid solution, neutralized with a saturated solution of sodium carbonate, rinsed with tap water, and dried in a forced-air drier at approximately $38 \stackrel{\circ}{ } \mathrm{C}$. Twenty $\mathrm{F}_{1}$ seeds were planted in a single $3.05 \mathrm{~m}$ row in the field at Stoneville in 2013. The majority of self-pollinated flowers aborted in the $F_{1}$ plants; thus, a combination of self-pollinated and open-pollinated seeds were used to generate the $F_{2}$ population. Approximately 500 acid-delinted $F_{2}$ seeds were planted in the field at Stoneville on 5 May 2014 in a single $150 \mathrm{~m}$ row with plants spaced approximately $0.3 \mathrm{~m}$ apart. The parental accessions were planted in $3.05 \mathrm{~m}$ single row plots for phenotypic comparison. Individual plants in the population were tagged during the mid-flowering stage, and flower corolla color was recorded for plants with flowers to determine if the population showed normal segregation for this trait. Yellow corolla color is dominant over white, and the population should show a 3:1 segregation ratio for this trait (Erpelding 2016). Seed cotton was harvested from one to 10 bolls on 23 September 2014, when the majority of the plants had reached maturity. The seed cotton from individual plants was ginned using a 10-saw laboratory gin to remove the majority of the lint fiber to characterize the presence of fuzz fiber on the seed coats. The presence or absence of fuzz fiber development on the seed coat for seeds from each $F_{2}$ plant was visually evaluated as described by Ware (1940). Plants were not specifically classified for the amount or density of fuzz fibers on the seeds (Erpelding 2016); however, the variation in fuzz fiber observed on the seed samples was noted. Plants were classified as fuzzless if seeds showed little or no fuzz fiber development across most of the seed coat. Seeds from plants showing fuzz fiber development across the majority of the seed coat were classified as fuzzy. The phenotypic segregation ratios for the fuzzless ovule trait and flower corolla color were tested using the chi-square test of significance with the Statistix 9 software package (Analytical Software, Tallahassee, FL, USA).

Ginned seeds from individual $\mathrm{F}_{2}$ plants were acid-delinted as previously described, and approximately $2 \mathrm{~g}$ of seeds were planted in single $3.05 \mathrm{~m}$ plots with approximately $0.91 \mathrm{~m}$ row spacing in the field at Stoneville on 30 April 2015. Seed cotton was harvested separately for five plants from each row in mid-October of 2015, ginned, and evaluated for the fuzzless ovule trait to confirm the $F_{2}$ phenotypic classification. From the $F_{3}$ generation, one seed cotton sample from each row was selected that showed a similar phenotype for the fuzzless ovule trait as the corresponding $F_{2}$ plant and planted as described above. This evaluation and selection process were conducted for the $F_{4}$ and $F_{5}$ generations to evaluate any environmental variation on the fuzzless trait. The parental genotypes were also included in the evaluation at each generation. 


\section{RESULTS}

Ginned seeds for $F_{1}$ plants derived from the cross PI $615733 \times$ PI 529729 showed slightly more fiber adhering to the seed coat compared to the fuzzless parental accession PI 615733 with greater tufts of fibers present on the chalazal and micropylar regions of the seeds. In comparison, seeds for PI 529729 were densely covered in fuzz fibers. The absence of fuzz fiber development on seeds from the $F_{1}$ plants would suggest the fuzzless phenotype is a dominant trait. The $F_{1}$ plants also showed flowers with yellow-colored corolla, which is the dominant phenotype for this trait. Flower corolla color segregation data for the PI $615733 \times \mathrm{PI} 529729 \mathrm{~F}_{2}$ population are presented in Table 1. Because the parental genotypes were different for maturity and the $F_{2}$ population showed segregation for maturity, not all plants had flowers that could be characterized at the time of the evaluation. Additionally, PI 529729 produces few flowers and $F_{2}$ plants showing this flowering characteristic were common in the population. As a result, corolla color data were collected from $289 \mathrm{~F}_{2}$ plants when the population was evaluated for this trait. The majority of the plants nevertheless showed a yellow-colored corolla, and these data supported the single gene model where yellow corolla color is dominant over white-colored corolla. These results indicate normal segregation for this trait in the population, although flower corolla color was not associated with the fuzzless trait as the two traits showed independent assortment (data not shown).

The gene model for the fuzzless ovule trait was less obvious. Seed germination rate and plant survival were approximately $80 \%$ for the $F_{2}$ population, and there were a few plants that showed poor growth and did not produce bolls or showed poor boll development. Overall, 409 plants produced one or more bolls to characterize the presence of fuzz fibers on the seed coats. There were two plants that produced one boll, whereas the majority of the plants produced 10 or more bolls. The density of fuzz fiber development observed on the seed coats was variable between plants within the population. There were 239 plants classified as fuzzless in which the majority of the fiber was removed during the ginning of these seed cotton samples (Table 2). For the plants classified as fuzzless, there were 46 plants that showed less fiber on the seed coats compared to the fuzzless parent, and the amount of fiber adhering to the chalazal and micropylar regions was also greatly reduced or nearly absent. Another 144 plants showed a phenotype similar to the fuzzless parent or $F_{1}$ plants where the majority of the fiber was removed from the seed coats with tufts of fiber remaining attached to the ends of the seeds. These $190 \mathrm{~F}_{2}$ plants were unambiguously classified as fuzzless. The remaining 49 plants that were classified as fuzzless showed more fiber on the seed coats compared to the fuzzless parent PI 615733 but much less fiber than the fuzzy PI 529729 parent. For the 170 plants classified as fuzzy, 15 plants showed profuse fuzz fiber development on the seeds, which was comparable to the fuzzy seeded parent PI 529729. There were another 113 plants unambiguously classified as fuzzy but showed a minor reduction in fiber on the seed coats compared to PI 529729. The remaining $42 \mathrm{~F}_{2}$ plants classified as fuzzy showed less fiber adhering to the seed coats; however, the majority of the seed coats showed more fuzz fiber development compared to plants rated as fuzzless. The greater number of plants classified as fuzzless would suggest that this phenotype is dominant; nevertheless, these data fail to support a single gene model (Table 2). The model that best supports these data was a two-gene model with incomplete dominance. This model showed a 9:7 segregation ratio and would indicate that at least one allele in the dominant state at each locus would be required for expression of the fuzzless ovule phenotype.

Table 1. Flower corolla color segregation data for the $F_{2}$ population derived from the Gossypium arboreum cross PI $615733 \times \mathrm{PI} 529729$

\begin{tabular}{lccc}
\hline Corolla Color & Number of Plants & $\boldsymbol{\chi}^{2}(3: 1$ segregation ratio) & $\boldsymbol{P}$-value \\
\hline Yellow & 213 & 0.26 \\
White & 76 & & 0.6104 \\
\hline
\end{tabular}

"Data for corolla color were collected for 289 plants from the population of 409 plants.

Table 2. Phenotypic segregation data for $409 \mathrm{~F}_{2}$ plants used to determine the inheritance of the fuzzless ovule trait for accession PI 615733 derived from the Gossypium arboreum cross PI $615733 \times$ PI 529729

\begin{tabular}{lcccc}
\hline Phenotype & Observed & Expected & $\chi^{2}$ & P-value \\
\hline Fuzzless & 239 & 307 & $59.854(3: 1$ ratio) & \\
Fuzzy & 170 & 102 & $0.794(9: 7$ ratio) & 0.0001 \\
\hline Fuzzless & 239 & 230 & & \\
Fuzzy & 170 & 179 & & \\
\hline
\end{tabular}


These results were confirmed in the $F_{3}$ to $F_{5}$ generations. The $F_{2}$ plants that showed a phenotype intermediate between the parental phenotypes segregated for the fuzz fiber phenotypes over multiple generations. In later generations, plants with phenotypes similar to the parental phenotypes were selected as the genes for the fuzzless ovule trait were fixed, and no environmental effects were observed as these same phenotypes were consistently recovered in following generations. Additionally, no variation for ovule fuzz fiber development was observed for the parental genotypes over multiple growing seasons suggesting no environmental effects on the fuzzless ovule trait.

\section{DISCUSSION}

More than 1600 accessions are maintained in the NPGS G. arboreum collection (Campbell et al. 2010). Accessions showing the fuzzless ovule phenotype occur at a low frequency in the collection with less than $2 \%$ of the accessions classified as fuzzless (unpublished data), although the collection has not been fully characterized for ovule fiber development. Most genetic studies of $G$. arboreum genotypes have reported one independent gene conferring the fuzzless ovule phenotype. A single dominant gene was reported for a $G$. arboreum landrace from China (Hutchinson 1935). This genotype showed the fuzzless phenotype with the presence of tufts of fibers on the chalazal and micropylar regions of the seeds. Du et al. (2018) also reported a single dominant gene for a Chinese $G$. arboreum accession and identified a region on chromosome 8 associated with fuzz fiber developed from a genome wide association study of 57 fuzzless ovule accessions. Further, Feng et al. (2019) fine mapped a single dominant gene for the G. arboreum fuzzless phenotype on chromosome 8 and identified GIR1 (GLABRA2interacting repressor) as a candidate gene. Liu et al. (2020) also reported that a single dominant gene conferred the fuzzless ovule trait for two accessions from the NPGS G. arboreum collection that was located on chromosome 8 and associated with the GIR1 candidate gene. Rong et al. (2005) reported a single recessive gene conferring the fuzzless phenotype for NPGS accession PI 529740, which also showed tufts of fibers adhering to the ends of the seeds. A single recessive gene was also reported for NPGS accession PI 615737 with tufts of fibers adhering to the micropylar region of the seeds (Erpelding 2016).

One study has reported complex inheritance of the fuzzless ovule trait (Erpelding 2017), in which three complementary genes with incomplete dominance for fuzz fiber development were shown to confer the fuzzless phenotype for NPGS accession PI 529708. Liu et al. (2020) also observed a significant deviation from a 3:1 segregation ratio for an $F_{2}$ population derived from this accession, suggesting the fuzzless trait was controlled by multiple loci. They also identified four additional accessions from the NPGS $G$. arboreum collection in which the population data did not support the single gene model. In the present study, mature seeds from $F_{1}$ plants derived from the cross PI $615733 \times$ PI 529729 lacked fuzz fiber development, indicating that the fuzzless ovule trait was dominantly inherited for PI 615733. A two-gene model with incomplete dominance for the fuzzless ovule phenotype showed the best fit for the segregation data from the $F_{2}$ population, and these results were confirmed over multiple generations. The results of the present study are supported by Liu et al. (2020). They identified two genes in G. arboreum that conferred the fuzzless ovule phenotype. All seven accessions they evaluated show a locus on chromosome 8 that Feng et al. (2019) had previously identified as conferring the fuzzless phenotype. Liu et al. (2020) reported three haplotypes at this locus with multiple sequence variations and considered this locus a major contributor to fuzz fiber development in G. arboreum. The other locus identified by Liu et al. (2020) was located on chromosome 12 and was associated with a MYB25-like candidate gene. They identified two haplotypes resulting from a SNP in the coding region and indicated this was a minor locus contributing to fuzz fiber development in G. arboreum.

Variation in fuzz fiber development on seeds was also observed for the PI $615733 \times$ PI $529729 \mathrm{~F}_{2}$ population evaluated in the present study, and interaction of the two genes could support this observation. Liu et al. (2020) showed that plants homozygous dominant for alleles at both loci produced fuzzless seeds and that more fuzz fiber developed on seeds for plants that were homozygous dominant for alleles at the chromosome 8 locus and homozygous recessive for alleles at the chromosome 12 locus. However, plants that were homozygous recessive for alleles at the chromosome 8 locus always produced fuzzy seeds, regardless of the genotype at the chromosome 12 locus. The results of the present study would also suggest a dosage effect and could explain the loss of the intermediate phenotypes over generations. The identification and characterization of plants from the population heterozygous at the loci would aid in testing this hypothesis. 
Data from the present study and previous studies would suggest genetic diversity for the fuzzless ovule trait within the NPGS G. arboreum collection. Further evaluation of the collection should be conducted to identify additional fuzzless accessions. Genetic characterization of these accessions would aid in further determining the genetic diversity for the fuzzless ovule trait in the collection. The sequence data for the two fuzzless ovule loci would be useful to aid in the characterization of the fuzzless accession identified in the present study and other fuzzless accessions from the G. arboreum collection. Fiber development in cotton genotypes results from the interaction of multiple genes and determining how the two genes interact to inhibit fuzz fiber development would be beneficial to understand how fiber development is regulated.

\section{ACKNOWLEDGEMENTS}

This research was funded by the USDA, ARS. Mention of trade names or commercial products in this article is solely for the purpose of providing specific information and does not imply recommendation or endorsement by the US Department of Agriculture. USDA is an equal opportunity provider and employer. The germplasm accessions used in this study are available from the USDA, NPGS cotton collection (https://npgsweb.ars-grin.gov/gringlobal/search.aspx).

\section{REFERENCES}

An C, Jenkins JN, Wu J, Guo Y and McCarty JC (2010) Use of fiber and fuzz mutants to detect QTL for yield components, seed, and fiber traits of upland cotton. Euphytica 172: 21-34.

Applequist WL, Cronn R and Wendel JF (2001) Comparative development of fiber in wild and cultivated cotton. Evolution \& Development 3: 3-17.

Bardak A and Bölek Y (2016) Inheritance of fuzz and lint fiber initiation of cotton (Gossypium hirsutum L.). Turkish Journal of Agriculture and Forestry 40: 606-612.

Bechere E, Turley RB, Auld DL and Zeng L (2012) A new fuzzless seed locus in an upland cotton (Gossypium hirsutum L.) mutant. American Journal of Plant Sciences 3: 799-804.

Campbell BT, Saha S, Percy R, Frelichowski J, Jenkins JN, Park W, Mayee CD, Gotmare V, Dessauw D, Giband M, Du X, Jia Y, Constable G, Dillon S, Abdurakhmonov IY, Abdukarimov A, Rizaeva SM, Abdullaev A, Barroso PAV, Pádua JG, Hoffmann LV and Podolnaya L (2010) Status of the global cotton germplasm resources. Crop Science 50: 1161-1179.

Desai A, Chee PW, May OL and Paterson AH (2008) Correspondence of trichome mutations in diploid and tetraploid cottons. Journal of Heredity 99: 182-186.

Dewan KM, Bhuiyan MSR, Robbani MG and Sonom M (2017) Genotypeenvironment interaction in yield of hill cotton genotypes. Bangladesh Journal of Plant Breeding and Genetics 30: 35-40.

Du X, Huang G, He S, Yang Z, Sun G, Ma X, Li N, Zhang X, Sun J, Liu M, Jia Y, Pan Z, Gong W, Liu Z, Zhu H, Ma L, Liu F, Yang D, Wang F, Fan W, Gong Q, Peng Z, Wang L, Wang X, Xu S, Shang H, Lu C, Zheng H, Huang S, Lin T, Zhu Y and Li F (2018) Resequencing of 243 diploid cotton accessions based on an updated $A$ genome identifies the genetic basis of key agronomic traits. Nature Genetics 50: 796-802.

Erpelding JE (2016) Determination of the genetic inheritance of the ovule fuzzless trait in Gossypium arboreum germplasm. Journal of Plant Breeding and Genetics 4: 1-5.
Erpelding JE (2017) Inheritance of the ovule fuzzless trait for Gossypium arboreum germplasm line PI 529708. International Journal of Plant Breeding and Genetics 11: 25-30.

Erpelding JE and Stetina SR (2018) Genetic characterization of reniform nematode resistance for Gossypium arboreum accession PI 417895. Plant Breeding 137: 81-88.

Feng X, Cheng H, Zuo D, Zhang Y, Wang Q, Liu K, Ashraf J, Yang Q, Li S, Chen $X$ and Song $G$ (2019) Fine mapping and identification of the fuzzless gene GaFzl in DPL972 (Gossypium arboreum). Theoretical and Applied Genetics 132: 2169-2179.

Guo WZ, Zhou BL, Yang LM, Wang W and Zhang TZ (2006) Genetic diversity of landraces in Gossypium arboreum L. race sinense assessed with simple sequence repeat markers. Journal of Integrative Plant Biology 48: 1008-1017.

Hande AS, Katageri IS, Jadhav MP, Adiger S, Gamanagatti S, Padmalatha KV, Dhandapani G, Kanakachari M, Kumar PA and Reddy VS (2017) Transcript profiling of genes expressed during fibre development in diploid cotton (Gossypium arboreum L.). BMC Genomics 18: 675.

Hebert JJ and Thibodeaux DP (1988) Cottonseed linters. Textile Research Journal 58: 714-719.

Huang G, Wu Z, Percy RG, Bai M, Li Y, Frelichowski JE, Hu J, Wang K, Yu JZ and Zhu Y (2020) Genome sequence of Gossypium herbaceum and genome updates of Gossypium arboreum and Gossypium hirsutum provide insights into cotton A-genome evolution. Nature Genetics 52: 516-524.

Hutchinson JB (1935) The genetics of cotton. Part XV. The inheritance of fuzz and lintlessness and associated characters in Asiatic cottons. Journal of Genetics 31: 451-470.

Hutchinson JB, Stephens SG and Dodds KS (1945) The seed hairs of Gossypium. Annals of Botany 9: 361-367.

Iqbal MA, Abbas A, Zafar Y and Rahman MU (2015) Characterization of indigenous Gossypium arboreum L. genotypes for various fiber quality traits. Pakistan Journal of Botany 47: 2347-2354. 
Kantartzi SK, Ulloa M, Sacks E and Stewart JM (2009) Assessing genetic diversity in Gossypium arboreum L. cultivars using genomic and ESTderived microsatellites Genetica 136:141-147.

Kim HJ and Triplett BA (2001) Cotton fiber growth in planta and in vitro. Models for plant cell elongation and cell wall biogenesis. Plant Physiology 127: 1361-1366.

Lee JJ, Hassan OSS, Gao W, Wei NE, Kohel RJ, Chen XY, Payton P, Sze SH, Stelly DM and Chen ZJ (2006) Developmental and gene expression analyses of a cotton naked seed mutant. Planta 223: 418-432.

Liu F, Zhou ZL, Wang CY, Wang YH, Cai XY, Wang XX, Zhang ZS and Wang KB (2015) Genetic diversity and relationship analysis of Gossypium arboreum accessions. Genetics and Molecular Research 14: 1452214529.

Liu X, Moncuquet P, Zhu Q-H, Stiller W, Zhang Z and Wilson I (2020) Genetic identification and transcriptome analysis of lintless and fuzzless traits in Gossypium arboreum L. International Journal of Molecular Sciences 21: 1675.

Ma XX, Zhou BL, Lü YH, Guo WZ and Zhang TZ (2008) Simple sequence repeat genetic linkage maps of A-genome diploid cotton (Gossypium arboreum). Journal of Integrative Plant Biology 50: 491-502.

Maqbool A, Abbas W, Rao AQ, Irfan M, Zahur M, Bakhsh A, Riazuddin S and Husnain T (2010) Gossypium arboreum GHSP26 enhances drought tolerance in Gossypium hirsutum. Biotechnology Progress 26: 21-25.

Mehetre SS, Aher AR, Gawande VL, Patil VR and Mokate AS (2003) Induced polyploidy in Gossypium: a tool to overcome interspecific incompatibility of cultivated tetraploid and diploid cottons. Current Science 84: 1510-1512.

Qin Y, Sun H, Hao P, Wang H, Wang C, Ma L, Wei H and Yu S (2019) Transcriptome analysis reveals differences in the mechanisms of fiber initiation and elongation between long- and short-fiber cotton (Gossypium hirsutum L.) lines. BMC Genomics 20: 633.

Qin YM and Zhu YX (2011) How cotton fibers elongate: a tale of linear cell-growth mode. Current Opinion Plant Biology 14: 106-111.

Romeu-Dalmau C, Bonsall MB, Willis KJ and Dolan L (2015) Asiatic cotton can generate similar economic benefits to Bt cotton under rainfed conditions. Nature Plants 1: 1-5.

Rong J, Pierce GJ, Waghmare VN, Rogers CJ, Desai A, Chee PW, May OL, Gannaway JR, Wendel JF, Wilkins TA and Paterson AH (2005) Genetic mapping and comparative analysis of seven mutants related to seed fiber in cotton. Theoretical and Applied Genetics 111: 1137-1146.

Stewart JM (1975) Fiber initiation on the cotton ovule (Gossypium hirsutum). American Journal of Botany 62: 723-730.

Turley RB and Kloth RH (2002) Identification of a third fuzzless seed locus in upland cotton (Gossypium hirsutum L.). Journal of Heredity 93: 359-364.

Wan Q, Guan X, Yang N, Wu H, Pan M, Liu B, Fang L, Yang S, Hu Y, Ye W, Zhang H, Ma P, Chen J, Wang Q, Mei G, Cai C, Yang D, Wang J, Guo W, Zhang W, Chen X and Zhang T (2016) Small interfering RNAs from bidirectional transcripts of GhMML3_A12 regulate cotton fiber development. New Phytologist 210: 1298-1310.

Wang S, Zhao GH, Jia YH and Du XM (2008) Cloning and characterization of a CAP gene expressed in Gossypium arboreum fuzzless mutant. Crop Science 48: 2314-2320.

Ware JO (1940) Relation of fuzz pattern to lint in an upland cotton cross. Journal of Heredity 31: 489-498.

Ware JO, Benedict LI and Rolfe WH (1947) A recessive naked-seed character in upland cotton. Journal of Heredity 38: 313-320.

Wendel JF (1989) New world tetraploid cottons contain old-world cytoplasm. Proceedings of the National Academy of Sciences, USA 86: 4132-4136.

Wendel JF, Olson PD and Stewart JM (1989) Genetic diversity, introgression, and independent domestication of old world cultivated cottons. American Journal of Botany 76: 1795-1806.

Zhang DY, Zhang TZ, Sang ZQ and Guo WZ (2007) Comparative development of lint and fuzz using different cotton fiber-specific developmental mutants in Gossypium hirsutum. Journal of Integrative Plant Biology 49: 1038-1046.

Zhang H-B, Li Y, Wang B and Chee PW (2008) Recent advances in cotton genomics. International Journal of Plant Genomics 2008: Article 742304.

Zhu L, Tyagi P, Kaur B and Kuraparthy V (2019) Genetic diversity and population structure in elite U.S. and race stock accessions of upland cotton (Gossypium hirsutum). Journal of Cotton Science 23: 38-47.

Zhu Q-H, Yuan Y, Stiller W, Jia Y, Wang P, Pan Z, Du X, Llewellyn D and Wilson I (2018) Genetic dissection of the fuzzless seed trait in Gossypium barbadense. Journal of Experimental Botany 69: 997-1009.

(cc) EY This is an Open Access article distributed under the terms of the Creative Commons Attribution License, which permits unrestricted use, distribution, and reproduction in any medium, provided the original work is properly cited. 